\title{
Impact of the COVID-19 Pandemic on Behaviour and Preference Changes in Relation to Selected Anabolic Androgenic Substances and Steroids: A Research Study
}

\author{
BEJTKOVSKÝ J. ${ }^{1}$, SNOPEK, P. ${ }^{2}$
}

1 | Tomas Bata University in Zlín, Faculty of Management and Economics, Department of Management and Marketing, Zlín, Czech Republic

2 | Tomas Bata University in Zlín, Faculty of Humanities, Department of Health Care Sciences, Zlín, Czech Republic
Citation | Bejtkovský, J., \& Snopek, P. (2021). Impact of the COVID-19 pandemic on behaviour and preference changes in relation to selected anabolic androgenic substances and steroids: A research study. Adiktologie, 21(2), 95-103. https://doi.org/10.35198/01-2021-002-0002
BACKGROUND: In December 2019, a severe acute respiratory syndrome caused by coronavirus 2 (SARSCoV-2 or COVID-19) broke out in China. The virus spread rapidly throughout the country and around the globe. In an effort to prevent the spread of the virus, all countries significantly limited social interaction, which also curbed all sports, social, and leisure activities. AlM: The main research objective of this paper was to determine whether there is a statically significant relationship between the potential interest in information retrieval and the subsequent possible change in behaviour and in preferences in relation to selected anabolic androgenic substances and steroids, before and after the global COVID-19 pandemic in the context of biological age, the highest level of education attained, and work status. METHODS: Secondary information sources were accessed via the citation database Web of Science and the Scopus citation and reference database. Selected mathematicalstatistical methods were used to analyse the data and interpret the findings. SAMPLE: The method of snowball sampling was used, allowing us to gather a pool of 127 respondents. RESULTS: The results suggest that there could be a statically significant relationship between the change in behaviour and in preferences in relation to selected anabolic androgenic substances and steroids before and after the global COVID-19 pandemic with regard to biological age and work status. It was also determined that the highest level of education attained by the respondents has no effect on this issue. CONCLUSION: The most common reason for the change in behaviour and in preferences associated with selected anabolic androgens and steroids before and after the COVID-19 pandemic was rapid muscle mass growth and an increase in muscle strength. The least intrinsically motivating reason was shortening the regeneration period of the body after a training session.

Keywords | COVID-19 Pandemic - Czech Republic - Fitness Centre - Anabolic Androgenic Drugs and Steroids - Sport processes that focus on value increase for a patient in a process of system creation to measure and control efficiency in health facilities in the Czech Republic". 


\section{INTRODUCTION}

Many countries and governments have been forced to implement isolation measures as a result of the SARS-CoV-2 (COVID-19) outbreak but subsequently such measures were adopted globally. The virus was first identified in December 2019, in Wuhan, China, and as of March 11, 2020, it has been officially listed as a pandemic by the World Health Organization (Zu et al., 2020).

The isolation protocols and subsequent measures have affected the functioning of the whole world in all areas, from working life through travel restrictions and bans, recreation to culture or the functioning of sports venues, clubs, and facilities such as gyms, stadiums, sports fields, halls, tracks, swimming pools, or fitness centres (Lim, 2020; Lim \& Pranata, 2021).

In this context, Lau et al. (2020) and Moris and Schizas (2020) state that as a result of preventing the spread of the COVID-19 virus, social contacts have been reduced, resulting in the curbing and reduction of all leisure, social, and sports activities.

Undoubtedly, the situation has had a negative effect not only on the mental state of the individual (Jeong et al., 2016; Reynolds et al., 2008) but also on the physical state of the human body.

For example, Kanayama and Pope (2018), Kanayama, Kaufman and Pope (2018), and Murray et al. (2016) and many others claim that the use of various types of anabolic androgenic substances and steroids is known among not only strength athletes, but also other people striving to improve their athletic performance or their physical, visual, and aesthetic appearance.

Anabolic androgenic substances and steroids can be characterized as a group of chemical derivatives of the male hormone testosterone. These substances are usually used in cycles lasting eight to 16 weeks. Among these cycles there are intervals without the use of these substances (Kanayama et al., 2003; Kanayama, Hudson \& Pope, 2008).

According to Cohen et al. (2007), Ip et al. (2011), Murray et al. (2016), and others, the internal motivation of people to use anabolic androgenic substances and steroids is mainly related to (a) an increase in muscle mass, strength, and endurance, (b) improving performance, (c) improved perception of the physical, visual, and aesthetic appearance of the individual, and (d) increasing one's self-confidence.

According to the new Czech Criminal Code (Act No. 40/2009 Coll.), Section 288, paragraph 1, it can be said that within the territory of the Czech Republic whoever manufactures, handles, imports, exports, transports, offers, sells, provides, or administers to another a substance with an anabolic or other hormonal effect for other than medical purposes, or whoever administers to another a method consisting of increasing oxygen transfer in the human body or uses another non-medical doping method against another shall be sentenced to imprisonment for up to one year. The next paragraphs of Section 288 then list the increasing penalties for cases of these crimes committed by an organized group (penalty rate from one to three years), when causing a serious injury (two to eight years) or even death (five to 12 years). In Section 289, paragraph 4 the Government of the Czech Republic stipulates what constitutes substances with anabolic and other hormonal effects and defines what is considered an amount larger than small according to Section 288 and what is considered a method of increasing oxygen transfer in the human body and other methods with a doping effect according to Section 288.

This research study aims to determine whether the COVID-19 pandemic, which resulted in a decline in fitness and sports activities, could affect the potential interest in information retrieval and the consequent possible change in behaviour and preferences regarding selected anabolic androgenic substances and steroids. Such an interest and change in behaviour and preferences are motivated by a rapid increase in muscle mass and the subsequent positive perception of the physical, visual, and aesthetic appearance of the individual, even though some of these substances are banned in the Czech Republic and have harmful effects on human health.

The aim of this article is to determine whether there is a statistically significant relationship between the potential interest in information and the possible subsequent change in behaviour and preferences related to selected anabolic androgens and steroids before and after the global COVID-19 pandemic in the context of one's biological age and one's highest level of educational attainment and employment status, that is, whether there could be a change in behaviour and preference related to selected anabolic androgenic substances and steroids after the COVID-19 pandemic. The secondary goal of the article is to define the motives for such a change in behaviour and preferences in connection with selected anabolic androgenic substances and steroids. The structure of the article shows a standard structure, i.e., defining the theoretical background of the research problem, followed by clarifying the research objectives, methodology, and data. The next section provides a presentation of the findings and a discussion. The last part contains the conclusion of the research study in hand.

\section{THEORETICAL BACKGROUND}

As reported by Jukic et al. (2020), Lau et al. (2020), Ranasinghe, Ozemek, and Arena (2020), and others, in December 2019 there was an outbreak of severe acute respiratory syndrome caused by coronavirus 2 (SARS-CoV-2 or COVID-19) in Wuhan and throughout Hubei Province. The virus spread rapidly throughout the country and then across the world, causing a variety of concerns and increasing global morbidity and mortality.

Pinto et al. (2020) add that COVID-19, as a disease caused by SARS-CoV-2, has been classified by the World Health Organization as a pandemic. In an effort to minimize the rate of infection, especially in groups at high risk of disease and mortality, extensive social distance and isolation policies have been adopted around the world.

Lau et al. (2020) state that with the ever-increasing number of confirmed cases, and the numbers infected, hospitalized, and 
deceased, the virus has turned into a global pandemic requiring physical and social distancing and the reduction or cancellation of most leisure, social, and sporting events and activities, as well as restrictions in industries, services, work and private life, bans on gatherings, the closing of public places, schools, and universities, home quarantine, and even placing entire cities and states in a complete lockdown, i.e., a ban on, and restrictions on, the free movement of people beyond their place of residence.

Lim (2020) and Lim and Pranata (2021) further argue that the COVID-19 pandemic has changed the daily habits of people around the world and has affected all areas, including sport, both professional and recreational. The closing of gyms, sports clubs, sports facilities, swimming pools, and fitness centres, along with the postponement of sporting events or international competitions, together with feelings of isolation while in quarantine and social distancing and not being able to exercise outdoors - all of the above may have a psychological, mental, physical, and behavioural impact on an individual.

Pinto et al. (2020) claim that during lockdown and physical and social distancing, most people, whether professional or non-professional athletes, have become accustomed to a sedentary lifestyle with less physical activity, fewer daily steps, failure to follow established daily eating habits or, last but not least, exercising less than before the COVID-19 pandemic.

In this context, Nieman (2020) believes that after the COVID-19 pandemic, the world will experience a major demographic shift towards an elderly, obese, and physically inactive population.

However, according to Halabchi, Ahmadinejad, and SelkGhaffari (2020), Chen et al. (2020), Jukic et al. (2020), and others, the return after the COVID-19 pandemic to traditional, wholesome exercise and sports activities will be a difficult but certainly internally motivating period not only for recreational sports, but also for elite sports. A rather long break from strength and endurance training leads to an increase in body fat, decreased muscle mass, loss of immunity, decreased mental acuity, insomnia, and depression, i.e., a weakening of physiological systems (the musculoskeletal, neuromuscular, respiratory, and cardiovascular systems) and physical abilities (strength, energy, flexibility, speed, and endurance).

With the return to pre-Covid life and the reopening of indoor sports facilities, clubs, and other facilities, the question arises of how to regain the previous form and once more take up the previously active lifestyle and physical activity. Not only active athletes, but also individuals who want to achieve visibly better performance, increase muscle mass, or improve the perception of their physical, visual, and aesthetic appearance in the shortest possible time after a lengthy interruption of their strength training could manifest a tendency towards the use of prohibited and harmful anabolic androgenic substances and steroids.

Anabolic androgens and steroids are synthetic testosterone derivatives with a longer duration of action than physiological androgens that have strong anabolic properties and relatively weak androgenic properties (Al-Falasi et al., 2008; Bahrke, Yesalis \& Brower, 1998).
In contrast, Mohammad (2014) states that anabolic androgenic substances and steroids increase protein synthesis in humans and actively affect skeletal muscle growth (anabolic effects) and boost the development of male sexual characteristics (androgenic effects).

In this context, Wilson (1998) argues that anabolic androgenic substances and steroids have been used in sports since the 1950s, especially in professional sports such as bodybuilding and athletics. These substances are becoming increasingly popular with young people, especially men, because of the muscle mass gain and the improved perception of one's physical, visual, and aesthetic appearance by oneself and others.

Al-Falasi et al. (2008), Kious (2008), Van Amsterdam, Opperhuizen, and Hartgens (2010), and others report that the nonmedical use of anabolic androgenic substances and steroids poses significant complications and risks, especially to one's health. The health risks include damage to the liver and kidneys. Long-term use damages the heart and causes enlarged organs. Women using anabolic androgenic substances and steroids for a long time usually have a masculine appearance; their voice deepens and they display virilizing symptoms. In men, the non-medical use of anabolic androgenic substances and steroids causes testicular shrinkage, erectile dysfunction and impotence, gynaecomastia, suppression of sperm production, malformed sperm, infertility, hormonal dysfunction, and the loss or cessation of testosterone production. Such substances also cause increased incidence of tooth decay or acne. People can also suffer from dangerous mood swings and psychosocial and psychiatric issues, especially excessive aggression and impaired concentration, when using anabolic androgens and steroids.

Anabolic androgenic substances and steroids are used dangerously and illegally not only by athletes striving for success, improved sports performance, and superiority over others or in sports competitions, but also by individuals looking to improve the perception of their physical, visual, and aesthetic appearance (Mohammad, 2014).

Within the territory of the Czech Republic, any handling of anabolic androgenic substances and steroids is, according to the New Criminal Code (Act No. 40/2009 Coll.), prohibited and punishable by imprisonment.

\section{RESEARCH OBJECTIVE,} METHODOLOGY, AND DATA

This research study seeks to examine the area of banned and harmful anabolic androgenic substances and steroids in the Czech Republic. On the basis of the literature that was consulted, it is clear that the respiratory syndrome caused by coronavirus 2 (SARS-CoV-2 or COVID-19) has affected the functioning and existence not only of the population and companies, but of whole societies, states, and entire continents.

The research study focuses on the field of sports that are gaining popularity especially among Generation Y and Generation Z in 
their attempt to build muscles and improve muscle flexibility, i.e., fitness. It is obvious that a return to power sports will be challenging after the COVID-19 pandemic and may not be immediately visible, fast enough, or high in quality and effectiveness.

As today's times are perceived as turbulent, it could be expected, in connection with the theoretical background presented above, that after the lockdown and with the absence of power sports as a result of the COVID-19 pandemic, there could be an increase in the level of interest in the use of banned and harmful anabolic androgenic substances and steroids.

The above- mentioned active interest would be prompted by a rapid growth and strengthening of muscle mass and improved perception of one's physical, visual and aesthetic appearance, not only in young individuals but in others too.

It should be noted that the authors of this research study do not in any way promote, encourage, or underestimate the use of banned and harmful anabolic androgenic substances and steroids.

This is a rather sensitive and confidential research area that is certainly interesting from various points of view. It also has a direct connection with, and a serious impact on, not only human health, but also ethics and legislation. Therefore, the entire research is viewed only hypothetically; i.e., if anabolic androgenic substances and steroids were allowed, how would this fact affect the attitude, behaviour, actions, and decisions of the participants in, or respondents to, this research study?

Participation in the research study was completely voluntary and all participants were informed prior to completing the questionnaire survey that under the New Criminal Code (Act No. 40/2009 Coll.) any handling of anabolic androgenic substances and steroids is prohibited and punishable by imprisonment.

Furthermore, it was explained to the participants in the research study that the research is viewed only hypothetically, i.e., if anabolic androgenic substances and steroids were allowed, how would this permission affect their attitudes, behaviour, actions, and decisions regarding anabolic androgens and steroids?

This research study presents only some of the identified partial results which are an integral part of the entire extensive research project.

The main aim of the research is to determine whether there is a statistically significant relationship between the potential interest in information retrieval and the subsequent possible change in behaviour and preferences regarding selected anabolic androgens and steroids before and after the global COVID-19 pandemic in the context of one's biological age, the highest level of education one has attained, and one's employment status, that is, whether there could be a change in behaviour and preferences related to selected anabolic androgenic substances and steroids after the pandemic. The secondary goal of the article is to define the real motives for such a change in behaviour and preferences in connection with selected anabolic androgenic substances and steroids.
Research question 1: Is there a statistically significant relationship between the potential interest in information retrieval and the consequent possible change in behaviour and preferences regarding selected anabolic androgens and steroids before and after the global COVID-19 pandemic and the biological age of the respondents?

Research question 2: Is there a statistically significant relationship between the potential interest in information retrieval and the consequent possible change in behaviour and preferences regarding selected anabolic androgens and steroids before and after the global COVID-19 pandemic and the highest level of education attained by the respondents?

Research question 3: Is there a statistically significant relationship between the potential interest in information retrieval and the consequent possible change in behaviour and preferences regarding selected anabolic androgens and steroids before and after the global COVID-19 pandemic and the working status of the respondents?

Research question 4: What are the existing motives for such a change in behaviour and preferences in connection with selected anabolic androgenic substances and steroids before and after the global COVID-19 pandemic?

Data collection was performed using an anonymous structured questionnaire survey. This survey was conducted online in May-June 2021. The pre-test of the questionnaire survey was conducted on a sample of ten respondents, followed by the main collection of the research data.

As this is a very sensitive topic, the snowball method was chosen as the method for selecting respondents. It was a reference, chain selection.

The research survey began with attendees of selected fitness centres being asked about their possible participation in the research study. To achieve non-distortion, an effort was made to select a heterogeneous primary sample based on segmentation criteria. The following criteria were included: geographical, demographic, and behavioural. The attendees of the selected fitness centres who agreed to participate were subsequently asked to share an online questionnaire survey, especially among people who they know also visit fitness centres.

The questionnaire survey itself consisted of several parts. The respondents' attitudes, opinions, and views were investigated with a five-point Likert scale of agreement, with the value of 1 indicating maximum disagreement with the statement and the value of 5 representing the respondent's maximum agreement.

The total number of correctly completed questionnaires for the purposes of mathematical-statistical methods was 127. Verification of the proposed research hypotheses was performed using Pearson's chi-square test. This test determines if there is a relationship between the selected statistical categories. This means that the occurrence of the specific variable A can assume the probability of the occurrence of the specific variable $\mathrm{B}$. If the value of $\mathrm{P}$ is lower than the chosen level of significance 
(usually 5\%, i.e., 0.05), the null hypothesis is rejected. The difference between the abnormalities found in the sample and the expected frequency is too large to be the result of a random sample, i.e., it is statistically significant.

The analysis of the data that was obtained was performed using the Microsoft Excel 2013 spreadsheet process and also through the IBM SPSS Statistics 23 statistical software.

Selected scientific methods, such as analysis, synthesis, induction, and deduction, were used in the processing of the secondary and primary findings.

\section{RESULTS AND DISCUSSION}

Table 1 shows the structure of the respondents who participated in the research study.

On the basis of Table 1, it can be said that $96 \%$ of the participants in the research study were men. They were mostly aged 20-29 (70.08\%), employed full-time $(43.31 \%)$ or studying (40.16\%), and the upper secondary level of education (41.73\%) prevailed among them. A total of $98 \%$ of the respondents trained regularly before the COVID-19 pandemic and a total of $96 \%$ of the respondents trained after the COVID-19 pandemic. Regular training means training at least three times a week.

Research question 1: Is there a statistically significant relationship between the potential interest in information retrieval and the consequent possible change in behaviour and preferences regarding selected anabolic androgens and steroids before and after the global COVID-19 pandemic and the biological age of the respondents?

Pearson's chi-square test was used to evaluate Research question 1 . When considering this dependence, the research survey showed that the $\mathrm{p}$-value was lower than the standard defined level of significance (0.05). Therefore, there is a statistically significant relationship between the potential interest in information retrieval and the subsequent possible change in behaviour and preferences related to selected anabolic androgens and steroids before and after the global COVID-19 pandemic and the biological age of the respondents $\left(X^{2}=33.972\right.$, $\mathrm{df}=9, \mathrm{p}<$ 0.05). The dependence was further analysed using the Cramer's V. Its value was 0.211 . It can therefore be said that in this case it is a weak relationship.

Research question 2: Is there a statistically significant relationship between the potential interest in information retrieval and the consequent possible change in behaviour and preferences regarding selected anabolic androgens and steroids before and after the global COVID-19 pandemic and the highest level of education attained by the respondents?

Pearson's chi-square test was used to verify Research question 2. The research showed that the p-value is equal to 0.526 , which is higher than the set limit value of 0.05 . Thus, the null hypothesis is not rejected at the $5 \%$ significance level. In this case, it can be argued that the highest level of education at- tained by the respondents does not affect the potential interest in seeking information and the subsequent possible change in behaviour and preferences related to selected anabolic androgens and steroids before and after the global COVID-19 pandemic $\left(X^{2}=16.964, \mathrm{df}=18, \mathrm{p}>0.05\right)$.

Research question 3: Is there a statistically significant relationship between the potential interest in information retrieval and the consequent possible change in behaviour and preferences regarding selected anabolic androgens and steroids before and after the global COVID-19 pandemic and the working status of the respondents?

The result of the verification of Research question 3 by Pearson's chi-square test shows that the respondent's employment status influences the potential interest in information retrieval and subsequent possible change in behaviour and preferences related to selected anabolic androgens and steroids before and after the global COVID-19 pandemic with a p-value equal to $0.015\left(X^{2}=21.733, \mathrm{df}=15, \mathrm{p}<0.05\right)$. The Cramer's $\mathrm{V}$ was used to determine the strength of the dependence. It can be concluded that this is a weak relationship (the value of the Cramer's V was 0.169).

Research question 4: What are the existing motives for such a change in behaviour and preferences in connection with selected anabolic androgenic substances and steroids before and after the global COVID-19 pandemic?

The research study also focused on determining the possible existence of real motives for a change in behaviour and preference in relation to selected anabolic androgens and steroids before and after the global COVID-19 pandemic. Through the questionnaire survey, participants were provided with possible reasons for changing their behaviour and preferences in connection with selected anabolic androgenic substances and steroids before and after the global COVID-19 pandemic. These possible reasons included: (a) a rapid growth and increase in muscle mass and strength, (b) improving one's fitness, performance, and endurance, (c) reducing the time needed for the regeneration of the body after training, (d) improved perception of one's physical, visual, and aesthetic appearance, (e) increasing one's self-confidence. The participants in the research study were instructed to select only one reason as the most relevant for them. Table 2 lists possible reasons for the change in their behaviour and preferences in relation to selected anabolic androgens and steroids before and after the global COVID-19 pandemic according to the respondents and their responses.

As can be seen from Table 2, the most common reason for the change in behaviour and preferences regarding selected anabolic androgens and steroids before and after the global COVID-19 pandemic was a rapid growth and increase in muscle mass and strength (51.18\%). On the other hand, according to the respondents, the least frequently selected reason was shortening of the time required for body regeneration after training $(0.79 \%)$.

This research study focuses on a possible change in behaviour and preferences related to selected anabolic androgenic sub- 
Table 1 | Structure of respondents addressed (authors' own design)

\begin{tabular}{|c|c|c|}
\hline Sex & Absolute frequency & Relative frequency (\%) \\
\hline Woman & 5 & 3.94 \\
\hline Man & 122 & 96.06 \\
\hline Total & 127 & 100.00 \\
\hline Biological age & Absolute frequency & Relative frequency $(\%)$ \\
\hline $15-19$ & 5 & 3.94 \\
\hline $20-29$ & 89 & 70.08 \\
\hline 30-39 & 17 & 13.39 \\
\hline 40-plus & 16 & 12.60 \\
\hline Total & 127 & 100.00 \\
\hline Work status & Absolute frequency & Relative frequency $(\%)$ \\
\hline Employed full-time & 55 & 43.31 \\
\hline Employed part-time & 9 & 7.09 \\
\hline Unemployed & 7 & 5.51 \\
\hline Self-employed & 3 & 2.36 \\
\hline Student & 51 & 40.16 \\
\hline Retired & 2 & 1.57 \\
\hline Total & 127 & 100.00 \\
\hline Highest level of education achieved & Absolute frequency & Relative frequency $(\%)$ \\
\hline Primary education & 9 & 7.09 \\
\hline Lower secondary education & 25 & 19.69 \\
\hline Upper secondary education - school-leaving exam (maturita) & 53 & 41.73 \\
\hline Higher vocational education & 2 & 1.57 \\
\hline Bachelor's degree & 20 & 15.75 \\
\hline Master's degree & 17 & 13.39 \\
\hline Doctorate & 1 & 0.79 \\
\hline Total & 127 & 100.00 \\
\hline Regular training pre-COVID-19 & Absolute frequency & Relative frequency $(\%)$ \\
\hline Yes & 125 & 98.43 \\
\hline No & 2 & 1.57 \\
\hline Total & 127 & 100.00 \\
\hline Regular training post-COVID-19 & Absolute frequency & Relative frequency $(\%)$ \\
\hline Yes & 122 & 96.06 \\
\hline No & 5 & 3.94 \\
\hline Total & 127 & 100.00 \\
\hline
\end{tabular}

stances and steroids and after the global COVID-19 pandemic in the context of selected respondent characteristics. The research results of Alsaeed and Alabkal (2015) support the results of this research study, where the degree of the highest level of education attained by the respondents does not affect their behaviour and preferences regarding selected anabolic androgenic substances and steroids.

The results of the research by Zoob Carter, Boardley, and van de Ven (2021) also confirm the impact of the COVID-19 pandemic on the use of anabolic androgenic substances and steroids and in general on the training of athletes. According to their results, the COVID-19 pandemic resulted in a lower frequency of training, but also a lower level of use of anabolic androgenic substances and steroids.
Singhammer (2013) states that several studies have been conducted to assess the knowledge and approach of people working out in fitness centres regarding the use of anabolic androgenic substances and steroids. A study carried out on a sample of 5,000 men and women in Denmark found that users of anabolic androgenic substances and steroids displayed more positive attitudes towards their use than those who do not work out.

Nilsson et al. (2004) report that a study among 4,000 male adolescents in Sweden showed that most of them do not perceive anabolic androgenic substances and steroids as harmful and believe that women prefer men with larger muscles. Furthermore, this study showed that users of anabolic androgens and steroids exercise more often in fitness centres and gyms and drink more alcohol than other adolescent men. 
Table 2| Possible reasons for a change in behaviour and preferences related to selected anabolic androgenic substances and steroids before and after the global COVID-19 pandemic (authors' own design)

\begin{tabular}{lcc}
\hline Possible reasons for change in behaviour & $\begin{array}{c}\text { Absolute } \\
\text { frequency }\end{array}$ & $\begin{array}{c}\text { Relative } \\
\text { frequency (\%) }\end{array}$ \\
\hline $\begin{array}{l}\text { Rapid growth and increase in muscle } \\
\text { mass and strength }\end{array}$ & 65 & 51.18 \\
$\begin{array}{l}\text { Improved perception of physical, } \\
\text { visual, and aesthetic appearance }\end{array}$ & 51 & 40.16 \\
$\begin{array}{l}\text { Improving one's fitness, performance, } \\
\text { and endurance }\end{array}$ & 6 & 4.72 \\
$\begin{array}{l}\text { Increasing one's self-confidence. } \\
\begin{array}{l}\text { Reducing the time needed for the } \\
\text { regeneration of the body after training }\end{array}\end{array}$ & 1 & 3.15 \\
\hline Total & $\mathbf{1 2 7}$ & $\mathbf{1 0 0 . 0 0}$ \\
\hline
\end{tabular}

Al-Falasi et al. (2008) conducted a survey of 150 attendees of fitness centres and gyms in the United Arab Emirates, which found that $7.0 \%$ of the respondents planned to try anabolic androgens and steroids, and $22.0 \%$ of the respondents attending fitness centres and gyms actively used anabolic androgens and steroids.

Mohammad (2014) conducted a study in Kuwait, in which he found that the prevalence of anabolic androgen and steroid use in Kuwaiti men was $12.0 \%$, with $37.0 \%$ of them being young adults under the age of 21 . Overall, $60.0 \%$ of fitness centre and gym attendees believe that anabolic androgenic substances and steroids have a limited negative impact on their health and a positive impact on the perception of their physical, visual, and aesthetic appearance.

The results of this research study also confirm the findings of Alsaeed and Alabkal (2015), 71.4\% of whose respondents intended to try selected anabolic androgenic substances and steroids in order to achieve an increase in muscle mass and strength, which is why they worked out. The results of the following studies contribute to further insights into this issue. Mohammad (2014); Santos, da Rocha, and da Silva (2011), and Singhammer (2013) state that the benefits of a rapid increase and growth in muscle mass and strength outweighed the potential risks of negative side effects of selected anabolic androgenic substances and steroids in their respondents.

\section{CONCLUSIONS}

The research study examines whether the COVID-19 pandemic, which resulted in a sharp decline in fitness and sports activities, could affect the potential interest in seeking information and the consequent possible change in behaviour and preferences regarding selected anabolic androgens and steroids. This interest, along with a change in behaviour and preferences, is motivated by a rapid increase in muscle mass and subsequent positive perception of the physical, visual, and aesthetic appearance of the individual, even though some of these substances are banned in the Czech Republic and have harmful effects on human health.
The primary objective of the research study was to identify whether there could be a relationship between the potential interest in information retrieval and subsequent possible behavioural changes and preferences related to selected anabolic androgens and steroids before and after the global COVID-19 pandemic in the context of selected characteristics of the respondents. These characteristics included their biological age, the highest level of education attained, and their employment status. The secondary goal of the article was to define the motives for why there could be a change in behaviour and preferences in connection with selected anabolic androgenic substances and steroids.

On the basis of the literature that was consulted, four research questions were formulated (RQ1, RQ2, RQ3, RQ4).

The results of the research study determined that there may be a statistically significant relationship between the potential interest in information retrieval and subsequent possible behavioural changes and preferences related to selected anabolic androgens and steroids before and after the global COVID-19 pandemic and the individual's biological age, but also their employment status. Furthermore, the results of the research study showed that the highest level of education attained by the respondents does not affect the potential interest in information retrieval and subsequent possible changes in behaviour and preferences in connection with selected anabolic androgens and steroids before and after the global COVID-19 pandemic. The research study also determined that the most common reason for changes in behaviour and preferences associated with selected anabolic androgens and steroids before and after the global COVID-19 pandemic would be a rapid growth and increase of muscle mass and strength. On the other hand, the least intrinsically motivating reason would be the reduction in time required to regenerate the body after training.

The results of the research study further support the fact that the COVID-19 pandemic may change the potential interest in information retrieval and spur a consequent possible change in behaviour and preferences regarding selected anabolic androgens and steroids, not only because of the reduced frequency of training but also because of other restrictions during the COVID-19 pandemic that were introduced globally. The value, contribution, and originality of the research study lies in the creation of reflections, debates, or research further addressing the consequences of the COVID-19 pandemic in the fields of sport, fitness, and also public health.

The research study itself was not without restrictions or limits, such as (a) the study has so far been carried out only in the Czech Republic; (b) only a reference, chain selection of respondents was chosen; (c) the data collection was carried out only through an online form; (d) the research sample of respondents could have been larger; (e) the duration of the research study could have been longer. Despite these limitations, the research study brings new information, data, and facts. 
Authors' contributions: Conceptualization: JB, PS; Introduction and Theoretical background: PS, JB; Methodology and Results: JB, PS; Final edition: PS, JB. Both authors contributed to the article and approved the final version of the manuscript.
Declaration of interest: The authors declare that they do not have any competing financial, professional, or personal interests from other parties.

\section{REFERENCES}

Al-Falasi, 0., Al-Dahmani, K., Al-Eisaei, K., Al-Ameri, S., Al-Maskari, F., Nagelkerke, N., \& Schneider, J. (2008). Knowledge, attitude and practice of anabolic steroids use among gym users in Al-Ain district, United Arab Emirates. The Open Sports Medicine Journal, 2, 75-81. http://doi.org/10.2174/1874387000802010075

Alsaeed, I., \& Alabkal, J. R. (2015). Usage and perceptions of anabolicandrogenic steroids among male fitness centre attendees in Kuwait - A crosssectional study. Substance Abuse Treatment, Prevention, and Policy, 10(33). http://doi.org/10.1186/s13011-015-0030-5

Bahrke, M. S., Yesalis, C. E., \& Brower, K. J. (1998). Anabolic-androgenic steroid abuse and performance-enhancing drugs among adolescents. Child and Adolescent Psychiatric Clinics of North America, 7(4), 821-838. http://www.ncbi.nlm.nih.gov/pubmed/9894044

Chen, P., Mao, L., Nassis, G. P., Harmer, P., Ainsworth, B. E., \& Li, F. (2020). Coronavirus disease (COVID-19): The need to maintain regular physical activity while taking precautions. Journal of Sport and Health Science, 9(2), 103-104. http://doi.org/10.1016/j.jshs.2020.02.001

Cohen, J., Collins, R., Darkes, J., \& Gwartney, D. (2007). A league of their own: Demographics, motivations and patterns of use of 1,955 male adult non-medical anabolic steroid users in the United States. Journal of the International Society of Sports Nutrition, 4(12). http://doi.org/10.1186/1550-2783-4-12

Czech Republic. Act No. 40/2009 Sb. of 8 January 2009, Zákon trestní zákoník. https://www.zakonyprolidi.cz/cs/2009-40

Halabchi, F., Ahmadinejad, Z., \& Selk-Ghaffari, M. (2020). COVID-19 epidemic: Exercise or not to exercise; That is the question! Asian Journal of Sports Medicine, 11(1), e102630. http://doi.org/10.5812/asjsm.102630

Ip, E. J., Barnett, M. J., Tenerowicz, M. J., \& Perry, P. J. (2011). The anabolic 500 survey: Characteristics of male users versus nonusers of anabolic-androgenic steroids for strength training. Pharmacotherapy, 31(8), 757-766. http://doi.org/10.1592/phco.31.8.757

Jeong, H., Yim, H. W., Song, Y. J., Ki, M., Min, J. A., Cho, J., \& Chae, J. H. (2016). Mental health status of people isolated due to Middle East Respiratory Syndrome. Epidemiology and Health, 38, e2016048. http://doi.org/10.4178/epih.e2016048

Jukic, I., Calleja-González, J., Cos, F., Cuzzolin, F., Olmo, J., Terrados, N., Njaradi, N., Sassi, R., Requena, B., Milanovic, L., Krakan, I., Chatzichristos, K., \& Alcaraz, P. E. (2020). Strategies and solutions for team sports athletes in isolation due to COVID-19. Sports, 8(4). http://doi.org/10.3390/sports8040056

Kanayama, G., Hudson, J. I., \& Pope, H. G. (2008). Long-term psychiatric and medical consequences of anabolic-androgenic steroid abuse: A looming public health concern? Drug and Alcohol Dependence, 98(1-2), 1-12. http://doi.org/10.1016/j.drugalcdep.2008.05.004

Kanayama, G., Kaufman, M. J., \& Pope, H. G. (2018). Public health impact of androgens. Current Opinion in Endocrinology, Diabetes, and Obesity, 25(3), 218-223. http://doi.org/10.1097/MED.000000000000040
Kanayama, G., \& Pope, H. G. (2018). History and epidemiology of anabolic androgens in athletes and non-athletes. Molecular and Cellular Endocrinology, 464, 4-13. http://doi.org/10.1016/j.mce.2017.02.039

Kanayama, G., Pope, H. G., Cohane, G., \& Hudson, J. I. (2003). Risk factors for anabolic-androgenic steroid use among weightlifters: A case-control study. Drug and Alcohol Dependence, 71(1), 77-86. http://doi.org/10.1016/S0376-8716(03)00069-3

Kious, B. M. (2008). Philosophy on steroids: Why the anti-doping position could use a little enhancement. Theoretical Medicine and Bioethics, 29(4), 213-234. http://doi.org/10.1007/s11017-008-9078-9

Lau, H., Khosrawipour, V., Kocbach, P., Mikolajczyk, A., Schubert, J., Bania, J., \& Khosrawipour, T. (2020). The positive impact of lockdown in Wuhan on containing the COVID-19 outbreak in China. Journal of Travel Medicine, 27(3), 1-7. http://doi.org/10.1093/jtm/taaa037

Lim, M. A. (2020). Exercise addiction and COVID-19-associated restrictions. Journal of Mental Health, 5(1-3). http://doi.org/10.1080/09638237.2020.1803234

Lim, M. A., \& Pranata R. (2021). Sports activities during any pandemic lockdown. Irish Journal of Medical Science, 190(1), 447-451. http://doi. org/10.1007/s11845-020-02300-9

Mohammad, H. (2014). Anabolic-androgenic steroids amongst Kuwaiti males College Student Journal, 48(1), 120-129. https://www.ingentaconnect.com/ content/prin/csj/2014/00000048/00000001/art00013

Moris, D., \& Schizas, D. (2020). Lockdown during COVID-19: The Greek success. In Vivo, 34(Suppl. 3), 1695-1699. http://doi.org/10.21873/invivo.11963

Murray, S. B., Griffiths, S., Mond, J. M., Kean, J., \& Blashill, A. J. (2016). Anabolic steroid use and body image psychopathology in men: Delineating between appearance- versus performance-driven motivations. Drug and Alcohol Dependence, 165, 198-202; http://doi.org/10.1016/j.drugalcdep.2016.06.008

Nieman, D. C. (2020). Coronavirus disease-2019: A tocsin to our aging, unfit, corpulent, and immunodeficient society. Journal of Sport and Health Science, 9(4), 293-301. http://doi.org/10.1016/j.jshs.2020.05.001

Nilsson, S., Spak, F., Marklund, B., Baigi, A., \& Allebeck. P. (2004). Attitudes and behaviors with regards to androgenic anabolic steroids among male adolescents in a county of Sweden. Substance Use \& Misuse, 39(8), 1183-1197. http://doi.org/10.1081/JA-120030060

Pinto, A. J., Dunstan, D. W., Owen, N., Bonfá, E., \& Gualano, B. (2020) Combating physical inactivity during the COVID-19 pandemic. Nature Reviews. Rheumatology, 16(7), 347-348. http://doi.org/10.1038/s41584-020-0427-z

Ranasinghe, C., Ozemek, C., \& Arena, R. (2020). Exercise and well-being during COVID-19 - Time to boost your immunity. Expert Review of Anti-Infective Therapy, 18(12), 1195-1200. http://doi.org/10.1080/14787210.2020.1794818

Reynolds, D. L., Garay, J. R., Deamond, S. L., Moran, M. K., Gold, W., \& Styra, R. (2008). Understanding, compliance and psychological impact of the SARS quarantine experience. Epidemiology and Infection, 136(7), 997-1007. http://doi.org/10.1017/S0950268807009156 
Santos, A. M., da Rocha, M. S. P., \& da Silva, M. F. (2011). Illicit use and abuse of anabolic-androgenic steroids among Brazilian bodybuilders. Substance Use \& Misuse, 46(6), 742-748. http://doi.org/10.3109/10826084.2010.534123

Singhammer, J. (2013). Attitudes toward anabolic-androgenic steroids among non-competing athletes in various types of sports - A cross-sectional study. Sport Science Review, 12(1-2), 109-128. http://doi.org/10.2478/ssr-2013-0006

Van Amsterdam, J., Opperhuizen, A., \& Hartgens, F. (2010). Adverse health effects of anabolic-androgenic steroids. Regulatory Toxicology and Pharmacology, 57(1), 117-123. http://doi.org/10.1016/j.yrtph.2010.02.001

Wilson, J. D. (1998). Androgen abuse by athletes. Endocrine Reviews, 9(2), 181-199. http://doi.org/10.1210/edrv-9-2-181

Zoob Carter, B. N., Boardley, I. D., \& van de Ven, K. (2021). The impact of the COVID-19 pandemic on male strength athletes who use non-prescribed anabolicandrogenic steroids. Frontiers in Psychiatry, 12. https://doi.org/10.3389/fpsyt.2021.636706

Zu, Z. Y., Jiang, M. D., Xu, P. P., Chen, W., Ni, O. O., Lu, G. M., \& Zhang, L. J. (2020). Coronavirus disease 2019 (COVID-19): A perspective from China. Radiology, 296(2). http://doi.org/10.1148/radiol.2020200490 